\title{
Review Article \\ Devastated Crops: Multifunctional Efficacy for the Production of Nanoparticles
}

\author{
G. Madhumitha and Selvaraj Mohana Roopan \\ Chemistry Research Laboratory, Organic Chemistry Division, School of Advanced Sciences, VIT University, Vellore, \\ Tamil Nadu 632 014, India \\ Correspondence should be addressed to G. Madhumitha; madhumitha.g@vit.ac.in and Selvaraj Mohana Roopan; \\ mohanaroopan.s@vit.ac.in
}

Received 1 February 2013; Accepted 24 March 2013

Academic Editor: Amir Kajbafvala

Copyright (C) 2013 G. Madhumitha and S. M. Roopan. This is an open access article distributed under the Creative Commons Attribution License, which permits unrestricted use, distribution, and reproduction in any medium, provided the original work is properly cited.

\begin{abstract}
Integration of green chemistry principles to nanotechnology is one of the key issues in nanoscience research. Biological methods were used to synthesize metal and metal oxide nanoparticles of specific shape and size since they enhance the properties of nanoparticles in greener route. Plant-mediated methods devoid the use of toxic chemicals in the synthetic protocols which has adverse effects on the environment. Owing to the rich biodiversity of plants and their potential secondary constituents, plants and plant parts have gained attention in recent years as medium for nanoparticles' synthesis. In this review, we present the current status of nanoparticles synthesis using devastated crops.
\end{abstract}

\section{Introduction}

Nanoscience is one of the most important research and development frontiers in modern science. In recent years, nanotechnology research is emerging as a cutting edge technology interdisciplinary with physics, chemistry, biology, material science, and medicine. The prefix "nano" is derived from the Greek word nano meaning "dwarf" that refers to things of one billionth $(109 \mathrm{~m})$ in size. The primary concept of nanotechnology was presented by Richard Feynman in a lecture entitled "There's plenty of room at the bottom" at the American Institute of Technology in 1959. Nanoparticles are usually from 0.1 to $1000 \mathrm{~nm}$ in each spatial dimension and are commonly synthesized using two strategies: top-down and bottom-up [1]. In top-down approach, the bulk materials are gradually broken down to nanosized materials (Figure 1). In the bottom-up approach, the atoms are assembled to molecular structures in nanometer range. The bottom-up approach is commonly used for chemical and biological syntheses of nanoparticles. On altering the physical nature of the nanoparticles, the properties of the bulk material differs.

These physical properties are caused by their large surface atom, large surface energy, spatial confinement, and reduced imperfections. Nanoparticles have advantages over bulk materials due to their surface plasmon resonance, enhanced Rayleigh scattering, and surface-enhanced Raman scattering in metal and metal oxide nanoparticles. Therefore, nanoparticles are considered as building blocks of the next generation of medicine, catalyst, optoelectronics, electronics, and various chemical and biochemical sensors $[2,3]$. The applications of nanoparticles in various fields are determined by their size, shape, and crystalline. Therefore, the synthesis of nanoparticles with different size and shape has been a challenge in nanotechnology.

There is a current drive to integrate all the green chemistry (Figure 2) approaches to design environmentally benign materials and processes. Rapid developments are taking place in the synthesis of metal and metal oxide nanomaterials and their surface modification for biological, medicine, and electronic applications. Numerous methodologies are formulated in the past to synthesize noble metal nanoparticles of particular shape and size depending on specific requirements. Even though various physical and chemical methods are extensively used to produce nanoparticles, the stability and the utilization of toxic chemicals is the subject of paramount concern. 
The usage of toxic chemicals and solvents in the synthesis limits the application of nanoparticles in the clinical fields. Therefore, the development of clean, biocompatible, nontoxic, and ecofriendly methods for nanoparticles' synthesis deserves merit. Biopreparation of nanoparticles as an emerging field of the intersection of nanotechnology and biotechnology has received increased attention due to a growing need to develop environmentally benign technologies in material syntheses. Several routes have been developed for biological or biogenic synthesis of nanoparticles from salts of the corresponding metals [4-7]. Biogenic synthesis is useful not only because of its reduced environmental impact $[8,9]$ when compared with some of the physicochemical production methods, but also because it can be used to produce large quantities of nanoparticles that are free of contamination and have a well-defined size and morphology. Biosynthetic routes can actually provide nanoparticles of a better defined size and morphology than some of the physicochemical methods of production [10]. In view of its simplicity, the use of live plants or whole-plant extract and plant tissue for reducing metal salts to nanoparticles has attracted considerable attention within the last 30 years [11-14]. The processes for making nanoparticles using plant extracts are readily available and less expensive. The plant extracts act as reducing and stabilizing agents in the fusion of nanoparticles. This is because different extracts contain different concentrations and combinations of organic reducing agents [15]. Although plant mediated syntheses are regarded as safe, cost-effective, sustainable, and environment friendly processes, they also have some drawbacks in cutting of the plants and plant parts [16]. For this reason, we looked for the alternate source for the synthesis of nanoparticles. Plant waste is considered as one of the pollutants, though it acts as organic fertilizers; consequently, there is a speed of vector borne diseases. Taking into account that the unutilized parts of the plant can also be employed in the nanoparticles preparation, in this review, we wish to report the utilization of crop devastation for the synthesis of nanoparticles.

\section{Green Chemical Approach for Nanoparticles Construction}

The nanoparticles were prepared by the mixing up of the metal salt with that of the extract (Figure 3 ). To produce the uniform size and shape of the nanoparticles, the researchers have to optimize the conditions such as the temperature, concentration of the extract, concentration of the metal salt, medium of the reaction, and time of the reaction; in this review we like to summarize some reports that pertain the synthesis of nanoparticles by using the unutilized parts of plants (Table 1).

2.1. Plant Latex and Gum as Precursors. The naturally available nontoxic, low-cost gum (Figure 4(a)) of olibanum was utilized for the silver nanoparticles synthesis [18]. An average of around $7.5 \pm 3.8 \mathrm{~nm}$ spherical nanoparticles was achieved by changing the reaction condition. The nanoparticles were confirmed by UV-visible spectroscopy, TEM, and X-ray

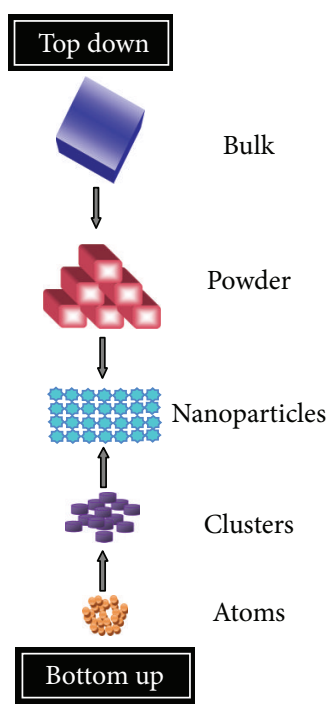

FIGURE 1: Approach for nanoparticles construction.

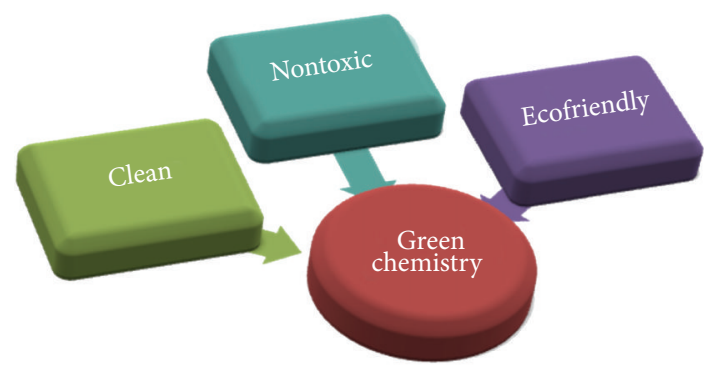

Figure 2: Advantages of green chemistry.

diffraction techniques. Patil et al., 2012, synthesized the silver nanoparticles in one-step solvent-free condition using Euphorbiaceae plant latex (Figure 4(b)). Around eight plant species were utilized for the synthesis of nanoparticles, out of which Jatropha gossypifolia, Jatropha curcas, and Euphorbia milii showed an average of $62 \pm 105 \mathrm{~nm}$. The formation of silver nanoparticles is due to the presence of phenolic compounds, flavonoids, tannins, and terpenoids. The obtained silver nanoparticles were checked for the antibacterial assays which showed a good inhibition against the selected pathogens [19]. An environmentally benign method for the synthesis of noble metal nanoparticles has been reported using aqueous solution of gum kondagogu (Cochlospermum gossypium). Both the synthesis and the stabilization of colloidal Ag, Au, and Pt nanoparticles have been accomplished in an aqueous medium containing gum kondagogu. The colloidal suspensions so obtained were found to be highly stable for prolonged period, without undergoing any oxidation. The Ag and Au nanoparticles formed were in the average size range of $5.5 \pm 2.5 \mathrm{~nm}$ and $7.8 \pm 2.3 \mathrm{~nm}$; while $\mathrm{Pt}$ nanoparticles were in the size ranges of $2.4 \pm 0.7 \mathrm{~nm}$, which was considerably smaller than Ag and Au nanoparticles [20]. The stem latex of Euphorbia nivulia was successfully used to induce room temperature/microwave synthesis of silver and copper nanoparticles even at high concentrations. The 
TABLE 1: Summary of nanoparticles preparation using devastate source.

\begin{tabular}{|c|c|c|c|}
\hline Sl. number & Source & Nanoparticles synthesized & References \\
\hline 1 & Olibanum & $\mathrm{Ag}$ & {$[18]$} \\
\hline 2 & Latex of J. gossypifolia, J. curcas, and E. milii & Ag & [19] \\
\hline 3 & Gum of Cochlospermum gossypium & $\mathrm{Ag}, \mathrm{Au}, \mathrm{Pt}$ & {$[20]$} \\
\hline 4 & Latex of Euphorbia nivulia & $\mathrm{Ag}, \mathrm{Cu}$ & {$[21]$} \\
\hline 5 & Lemon peel & $\mathrm{Ag}$ & {$[22]$} \\
\hline 6 & Orange peel & $\mathrm{Ag}$ & {$[23]$} \\
\hline 7 & Citrus sinensis peel & $\mathrm{Ag}, \mathrm{Au}$ & {$[24-26]$} \\
\hline 8 & Banana peel extracts & $\mathrm{Pd}, \mathrm{Ag}$ & {$[27,28]$} \\
\hline 9 & Neem kernel & $\mathrm{Ag}$ & [29] \\
\hline 10 & Annona squamosa & $\mathrm{Pd}, \mathrm{TiO}_{2}$ & {$[30-32]$} \\
\hline 11 & B. hispida & Ag & [33] \\
\hline 12 & C. infundibuliformis & $\mathrm{Ag}$ & {$[34,35]$} \\
\hline 13 & H. rosa-sinensis & $\mathrm{Au}, \mathrm{Ag}$ & {$[36]$} \\
\hline 14 & Corn cob & Cellulose-based nanoparticles & [37] \\
\hline 15 & Psidium guajava & $\mathrm{Ag}$ & {$[38]$} \\
\hline 16 & E. prostrate & $\mathrm{Ag}$ & [39] \\
\hline 17 & P. juliflora & Ag & {$[40]$} \\
\hline 18 & Piper betel leaf & $\mathrm{Ag}$ & {$[41]$} \\
\hline 19 & J. curcas & $\mathrm{Ag}$ & {$[42]$} \\
\hline 20 & Manihot esculenta & $\mathrm{Cu}_{2} \mathrm{O}$ & {$[43,44]$} \\
\hline 21 & A. hypogaea & $\mathrm{Ag}, \mathrm{Cu}_{2} \mathrm{O}$ & {$[45,46]$} \\
\hline 22 & Pollen grains & $\mathrm{TiO}_{2}$ & [47] \\
\hline 23 & Rice hulls & $\mathrm{LiSi}$ & {$[48]$} \\
\hline 24 & Pomegranate peel & $\mathrm{Ag}$ & [49] \\
\hline 25 & Palm oil effluent & $\mathrm{Au}$ & {$[50]$} \\
\hline 26 & Rice husk & $\mathrm{SiC}, \mathrm{Si}$ & {$[51,52]$} \\
\hline 27 & Rice hull & $\mathrm{Si}$ & {$[53]$} \\
\hline 28 & V. radiata, A. hypogaea, C. tetragonolobus, Zea mays, P. glaucum, and S. vulgare & Ag & [54] \\
\hline 29 & Cocos nucifera coir extract & Ag & {$[17]$} \\
\hline
\end{tabular}

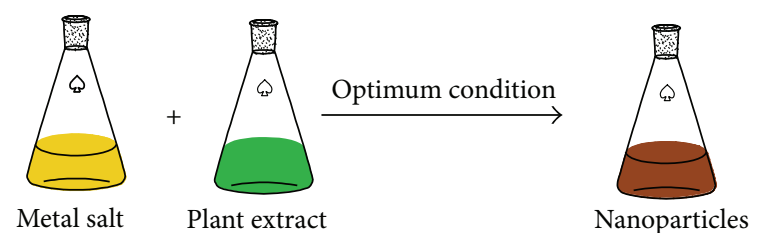

FIgURE 3: Preparation of nanoparticles using devastated crops.

major component of the latex was euphol and is assumed to be the reducing moiety. The stabilization is assisted by certain peptides and terpenoids present within the latex. The fast and simple process has high reproducibility and leads to the formation of nanoparticles with 5-10 nm diameter. The one-step synthesis can be extended for other metals. The nanoparticles' solutions being completely free of toxic chemicals can be directly used for antimicrobial tests. The as-synthesized solutions of both metals exhibited excellent bactericidal action against both Gram-negative and Grampositive bacteria well below the in vitro cytotoxicity concentration. The noncytotoxic metal-latex aqueous solution offers a rational approach towards antimicrobial application and for integration into biomedical devices [21].

2.2. Fruit Peel as an Agent. Prathna et al., 2011, in their studies reported the rapid synthesis of silver nanoparticles at room temperature by treating silver ions with the Citrus lemon (lemon) extract (Figure 4(c)). The effects of various process parameters like the reductant concentration, mixing ratio of the reactants, and the concentration of silver nitrate were taken into account. In the standardized process, $10^{-2} \mathrm{M}$ silver nitrate solution was interacted for $4 \mathrm{~h}$ with lemon juice in the ratio of $1: 4$. The formation of silver nanoparticles was confirmed by surface plasmon resonance as determined by UV-visible spectra in the range of $400-500 \mathrm{~nm}$. X-ray diffraction analysis revealed the distinctive facets $(111,20$ 0, 22 0, 22 2, and 311 planes) of silver nanoparticles. Citric acid was the principal reducing agent for the nanosynthesis process. Silver nanoparticles below $50 \mathrm{~nm}$ with spherical and spheroidal shapes were observed from transmission electron microscopy [22]. Konwarh et al., 2011, prepared aqueous extract of orange peel (Figure 4(d)) at basic $\mathrm{pH}$ which was exploited to prepare starch-supported nanoparticles under 


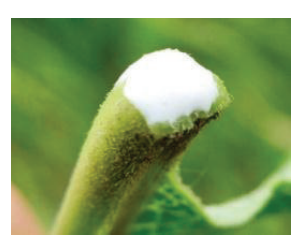

(a)

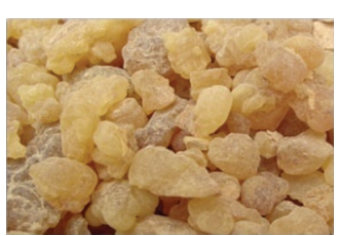

(b)

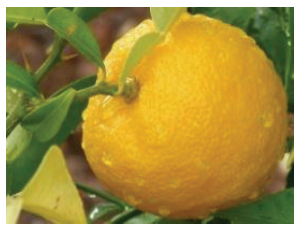

(c)

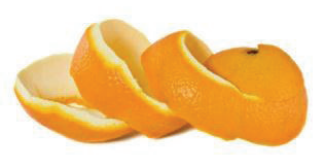

(d)

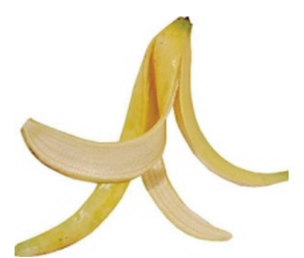

(e)

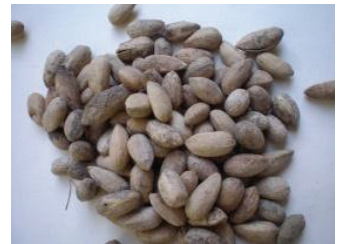

(f)

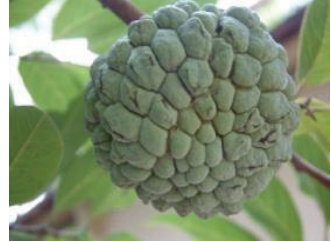

(g)

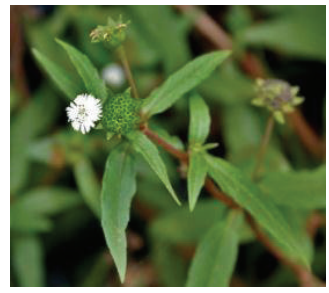

(j)

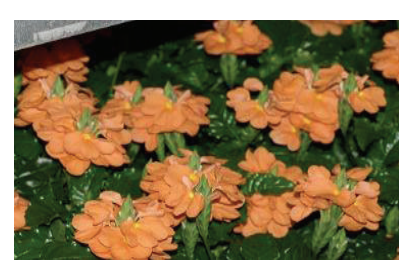

(h)

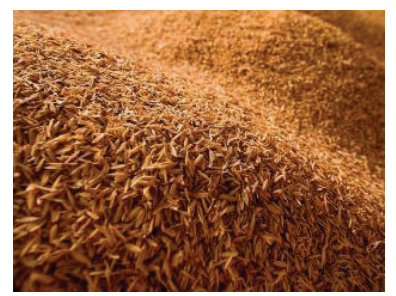

(k)

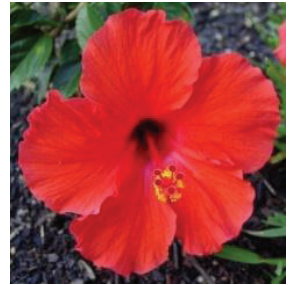

(i)

FIGURE 4: Various devastated sources for the preparation of nanoparticles.

ambient conditions. The compositional abundance of pectins, flavonoids, ascorbic acid, sugars, carotenoids, and myriad other flavones may be envisaged for the effective reductive potential of orange peel to generate silver nanoparticles. The nanoparticles were distributed within a narrow size spectrum of 3-12 nm with characteristic Bragg's reflection planes of fcc structure and surface plasmon resonance peak at $404 \mathrm{~nm}$. Antilipid peroxidation assay using goat liver homogenate and DPPH scavenging test established the antioxidant potency of the silver nanoparticles [23]. An unreported green chemistry route for the synthesis of silver nanoparticles using extract derived from Citrus sinensis peel and their antibacterial activity are described [24]. The authors have extracted the phytoconstituents from sun-dried peel of Citrus sinensis and prepared gold and silver nanoparticles in aqueous medium. The prepared nanoparticles are stable, monodispersed, and predominantly of spherical shape of size $14-20 \mathrm{~nm}$. The phytoconstituents with functional groups of alcohol, ketones, aldehyde, and amines play an important role in the stability of the nanoparticles. These nanoparticles find applications in nanotechnology and medicine [24-26]. Carlson et al. [24], Singh et al. [25], and Kaviya et al. [26] studied the characteristic surface plasmon resonance band of biogenic AgNPs that occurs at $445 \mathrm{~nm}$ and $424 \mathrm{~nm}$ for reaction carried out at room temperature and $60^{\circ} \mathrm{C}$, respectively. The FTIR confirms the water-soluble fractions in the extract played complicated roles in the bioreduction of the precursors and shape evolution of the nanoparticles. In HRTEM, the size of the nanoparticles was $35 \pm 2 \mathrm{~nm}$ with an average size of
$10 \pm 1 \mathrm{~nm}$, and in XRD, the size of the nanoparticles was thus determined to be about $33 \pm 3 \mathrm{~nm}$ and $8 \pm 2 \mathrm{~nm}$ for AgNPs synthesized at $25^{\circ} \mathrm{C}$ and $60^{\circ} \mathrm{C}$, respectively. The presence of the elemental silver can be observed in the graph obtained from EDAX analysis, which also supports the XRD results. This indicates the reduction of silver ions to elemental silver. The AgNPs exhibited good antibacterial activity against both Gram-negative and Gram-positive bacteria. But it showed higher antibacterial activity against $E$. coli and $P$. aeruginosa (Gram-negative) than S. aureus (Gram-positive). The effect of antibacterial activity is high in the case of silver nanoparticles synthesized at $60^{\circ} \mathrm{C}$ compared to $25^{\circ} \mathrm{C}$ because of being smaller in size. The high bactericidal activity is certainly due to the silver cations released from $\mathrm{Ag}$ nanoparticles that act as reservoirs for the $\mathrm{Ag}^{+}$bactericidal agent.

2.2.1. Banana Peel Utilization. An important example of day-to-day life fruit waste is the banana peel (Figure 4(e)). The banana pulp is consumed air and the peels are usually discarded. In the literature there are a few applications of these peels [55-57]. The abundantly available agricultural waste that is composed of polymers such as lignin and pectins [27] could be applied in the synthesis of palladium nanoparticles. The air-dried banana peel extracts (BPE) were used for reducing silver nitrate. Silver nanoparticles were formed when the reaction conditions were altered with respect to $\mathrm{pH}, \mathrm{BPE}$ content, concentration of silver nitrate, and incubation temperature. The colourless reaction mixtures 


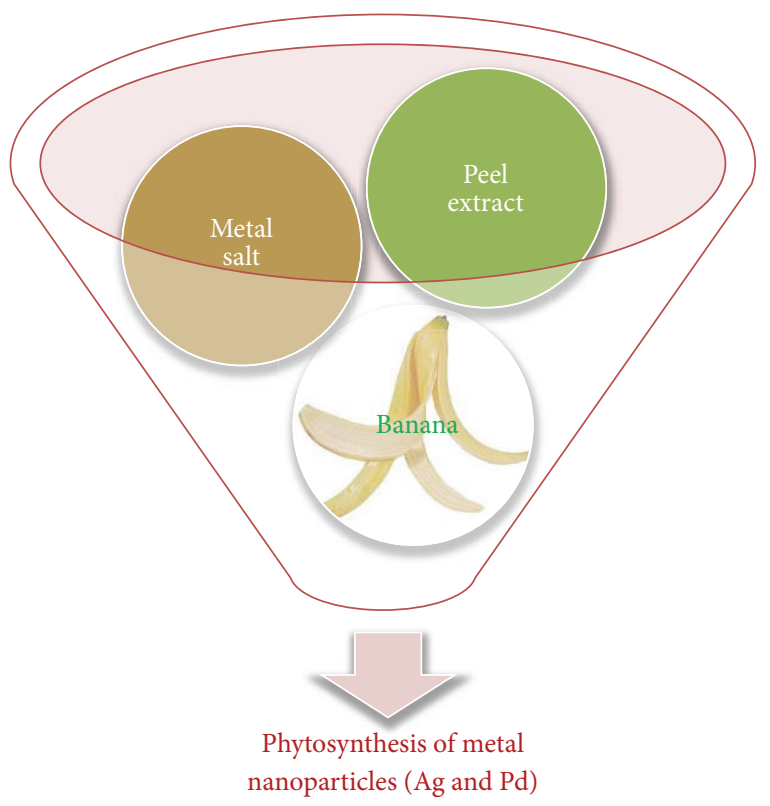

Figure 5: Role of banana peel for the phytosynthesis of metal nanoparticles.

turned brown and displayed UV-visible spectra characteristic of silver-nanoparticles. Scanning electron microscope (SEM) observations revealed the predominance of silver nanosized crystallites after short incubation periods [58]. Also Bankar et al., 2010, used agricultural waste banana peel for the synthesis of palladium nanoparticles (Figure 5). The UV-visible absorption spectra of reaction mixtures, the control samples, showed a distinct peak at around $400 \mathrm{~nm}$ indicating the existence of Pd(II) [28]. BPE could be also useful as an efficient green material for the rapid and consistent synthesis of gold nanoparticles. A variation in reaction conditions brought about the synthesis of a variety of nanoparticles displaying vivid colours and typical UV-vis spectra. The XRD analysis showed predominant peaks at (1 111$)$ and $\left(\begin{array}{lll}2 & 0 & 0\end{array}\right)$ indicative of the presence of microcubes and microwires displaying fcc lattice structure. BPE mediated structured patterning of the nanoparticles into microcubes and microwire networks. The BPE-derived gold nanoparticles displayed antifungal and antibacterial activity towards the test pathogenic fungi and most of the bacterial cultures [59].

2.3. Preparation of Nanoparticles Using Neem Kernel. Shukla et al., 2012 has used the neem kernel (Figure 4(f)) extracts for the synthesis of nanoparticles. The X-ray diffraction (XRD) pattern suggests the formation and crystalline of nanosilver. The average particle size of silver nanoparticles was $8.25 \pm$ $1.37 \mathrm{~nm}$ as confirmed by transmission electron microscopy (TEM). The obtained nanoparticles act as a sensor for the detection of hydrogen peroxide in water [29].

2.4. Annona squamosa Fruit Peel. Annona squamosa L. (Annonaceae), commonly known as custard apple, is a multipurpose tree with edible fruits and a source of medicinal and industrial products. It is known as its sweet soup is reported to have several medicinal actions such as insecticidal and antihelminthic activities. It is used for antimicrobial, anti-insecticidal, antifertility, antitumour, anti-inflammatory, and antiulcer properties. Also, the efficacy of adulticidal and larvicidal activity of fruit peel aqueous extract of A. squamosa and its compounds against hematophagous parasites is reported [30]. Spherical shape Palladium nanoparticles of particle sizes ranging from $80 \pm 5 \mathrm{~nm}$ are reported using Annona squamosa (Figure 4(g)) aqueous peel extract [31]. The report reveals that the presence of secondary metabolites contains $-\mathrm{OH}$ group which is responsible for the reduction of palladium(II) to palladium(0). Also, they have reported the synthesis of silver nanoparticles with irregular spherical shape of nanoparticles ranging from 20 to $60 \mathrm{~nm}$ [60]. Hence, they proposed that the reaction between broth of Annona squamosa peel extract and the $\mathrm{Pd}(\mathrm{II})$ species might occur according to the equation described in Figure 6. Further, they extended their work on environmentally benign, nontoxic, and renewable source of $A$. squamosa being used as an effective source for the synthesis of rutile $\mathrm{TiO}_{2}$ nanoparticles [32]. The XRD pattern of the sample showed the presence of peaks $2 \theta=27.42^{\circ}, 36.10^{\circ}, 41.30^{\circ}$, and $54.33^{\circ}$, which is found to be that of the rutile form. The main peak of $\theta=27.42^{\circ}$ matches the $\left(\begin{array}{lll}1 & 1 & 0\end{array}\right)$ crystallographic plane of rutile form of $\mathrm{TiO}_{2}$ nanoparticles. They proved that particles are distributed in the size of $23 \pm 2 \mathrm{~nm}$ ranges, and also they have suggested the mechanistic pathway for the formation of $\mathrm{TiO}_{2}$ nanoparticles (Figure 7) [32]. Thus, A. squamosa was proved to have multifunctional efficacy towards the preparation of metal and metal oxide nanoparticles (Figure 8).

2.5. Seed as Source. B. hispida seed extract is a good source of carbohydrates, amino acids, proteins, and phenolic compounds. The position of SPR band in UV-vis spectra is sensitive to particle size, shape, local refractive index, and its interaction with medium. At room temperature, the reduction is slow and hence the SPR band is broad, which shows the formation of particles with broad size distribution. The SPR band is shifted towards the shorter wavelength region from $548 \mathrm{~nm}$ to $544 \mathrm{~nm}$ which shows a decrease in particle size. The XRD peaks are found to be broad indicating the formation of silver nanoparticles. Five diffraction peaks are observed which can be indexed to the (lllll $\left.\begin{array}{lll}1 & 1\end{array}\right),\left(\begin{array}{lll}2 & 0 & 0\end{array}\right)$,

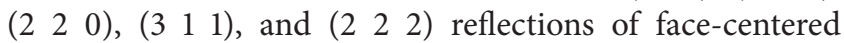
cubic structure of metallic gold, respectively, revealing that the synthesized gold nanoparticles are composed of pure crystalline gold. The peak corresponding to (1 111$)$ plane is more intense than the other planes suggesting that $\left(\begin{array}{lll}1 & 1 & 1\end{array}\right)$ is the predominant orientation as confirmed by the highresolution TEM measurement. Crystalline nature of NPs is evident from bright circular spots in the SAED pattern, clear lattice fringes in the HRTEM images, and peaks in the XRD pattern. From FTIR spectrum, it is found that the possible reducing agent is polyols and the aping material responsible for stabilization is the proteins present in the extract [33]. 


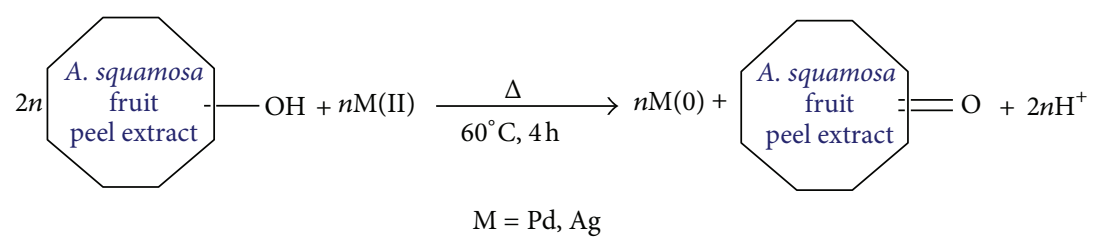

Figure 6: Biosynthesis of Pd and Ag nanoparticles using A. squamosa fruit peel extract.

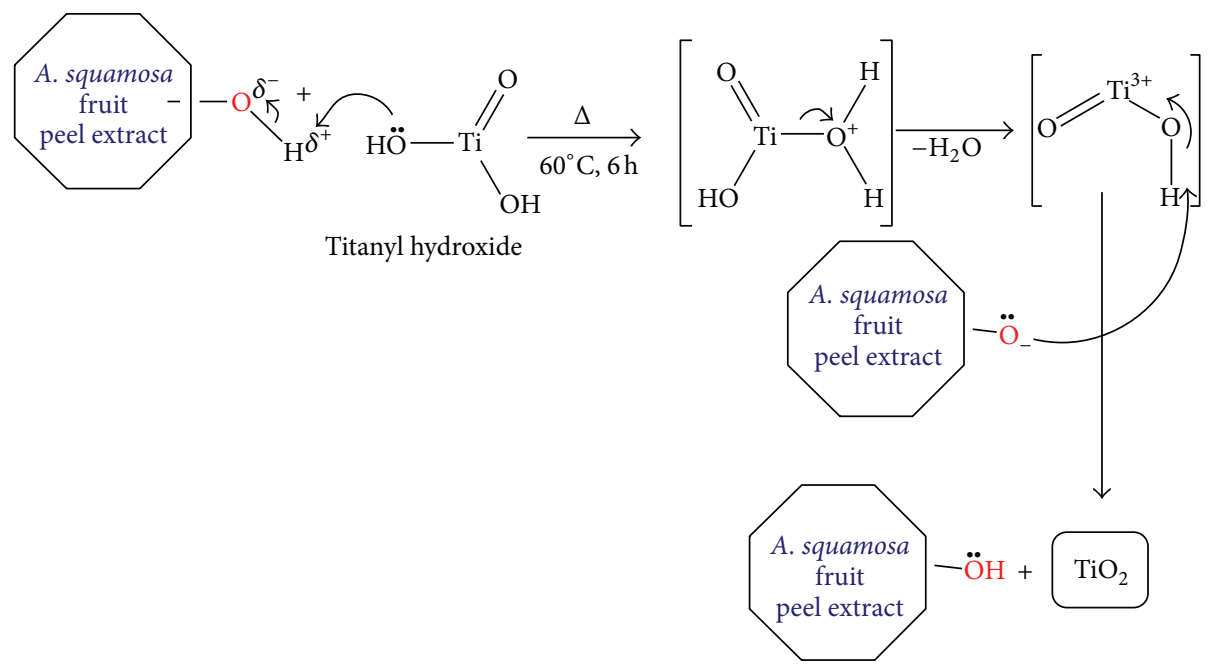

FIGURE 7: Mechanistic pathway for the formation of $\mathrm{TiO}_{2}$ nanoparticles.

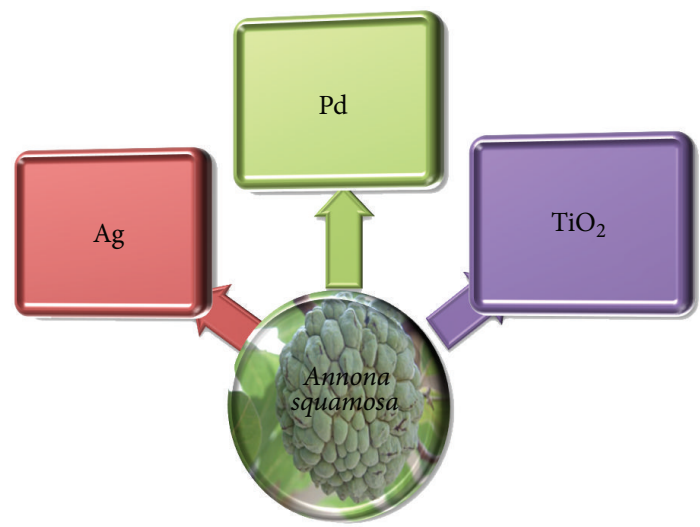

FIGURE 8: Multifunctional efficacy of A. squamosa towards nanoparticles preparation.

2.6. Leaf Extracts Assisted Preparation. C. infundibuliformis, an ornamental plant, is marketed as such. The species is often grown to beautify kitchen gardens as it is small in size and sprouts attractive flowers. The preliminary phytochemical suggested the presence of phytoconstituents such as phenolics, flavonoids, and tannins. Also C. infundibuliformis showed medicinal properties such as antibacterial, antifungal, anticandidal, hepatoprotective, and larvicidal activities $[34,35,61]$. The formation of AgNPs by a biological route employing C. infundibuliformis leaf extract (Figure 4(h)) has been investigated [62]. The silver nanoparticles were formed in $1 \mathrm{~h}$ by stirring at room temperature and a yellowish-brown color was developed. The formation of AgNPs was confirmed by surface Plasmon spectra and absorbance peaks at $457 \mathrm{~nm}$ with face-centered cubic structure. The AgNPs formed were flake-like in shape and the average particle size was about $38 \mathrm{~nm}$. Philip in 2010 described the biological synthesis of gold and silver nanoparticles of various shapes using the leaf extract of $H$. rosa-sinensis (Figure 4(i)) that are reported. The size and shape of Au nanoparticles are modulated by varying the ratio of metal salt and extract in the reaction medium [36].

The high phenol content of the hot water extract of olive leaves having strong antioxidant properties helped in the reduction of gold cations to AuNPs. The characterization of AuNPs revealed that the morphology of the AuNPs depends on the extract concentration and $\mathrm{pH}$ of the used medium. At higher concentration of the extract and basic $\mathrm{pH}$, the pseudospherical particles are capped by phytochemicals [63]. Kumar et al., 2010, have reported the cellulose-based nanoparticles (CPNs) from corn cob raw material by treating it with sodium hydroxide in the range $0-24 \%$ of sodium hydroxide concentration. The obtained sample was washed with deionized water, disintegrated, and filtered through 80 mesh screens. The powder thus obtained was delignified by acidified sodium chlorite and dried in a vacuum oven to a constant weight. Dried powder was further separated by 270 mesh screens. By this method, an average particle size was approximately equal to $22 \mathrm{~nm}$ which was confirmed by TEM [37]. 
Rajani et al., 2009, checked the four pulse crop plants and three cereal crop plants and compared their extracellular synthesis of metallic silver nanoparticles. Stable silver nanoparticles were formed by treating aqueous solution of $\mathrm{AgNO}_{3}$ with the plant leaf extracts as reducing agent at temperatures $50^{\circ} \mathrm{C}-95^{\circ} \mathrm{C}$. SEM and EDAX analysis confirm the size of the formed silver nanoparticles to be in the range of 50-200 nm [64]. Microwave assisted method has been adopted for the preparation of silver nanoparticles using guava (Psidium guajava) leaf extract. The obtained Ag nanoparticles size is $26 \pm 5 \mathrm{~nm}$. The reaction occurs very rapidly as the formation of spherical nanoparticles is almost completed within $90 \mathrm{~s}$ which shows the efficiency of the extract [38].

The larvicidal activity of synthesized silver nanoparticles (AgNPs) utilizing aqueous extract from E. prostrate was investigated against fourth instar larvae of filariasis vector, Culex quinquefasciatus say, and malaria vector, Anopheles subpictus Grassi. SEM analyses of the synthesized AgNPs were clearly distinguishable and measured $35-60 \mathrm{~nm}$ in size. Larvae were exposed to varying concentrations of aqueous extract of synthesized AgNPs for $24 \mathrm{~h}$. The maximum efficacy was observed in crude aqueous and synthesized AgNPs against $C$. quinquefasciatus $\left(\mathrm{LC}_{50}=27.49\right.$ and $4.56 \mathrm{mg} / \mathrm{L} ; \mathrm{LC}_{90}$ $=70.38$ and $13.14 \mathrm{mg} / \mathrm{L})$ and against $A$. subpictus $\left(\mathrm{LC}_{50}=27.85\right.$ and $5.14 \mathrm{mg} / \mathrm{L} ; \mathrm{LC}_{90}=71.45$ and $25.68 \mathrm{mg} / \mathrm{L}$ ), respectively [39]. Prosopis juliflora is a locally available plant species and has not been explored as having a pharmaceutical use. P. juliflora trees survive in dry climates because their root system can often extend more than 100 feet, so that they can outlast everything else and also they can survive along the coastal area. Hence the author Raja et al., 2012, has utilized the leaves of $P$. juliflora for the synthesis of silver nanoparticles and checked its antimicrobial activities [40].

Piper betel leaf petiole extract and ionic surfactants such as cetyltrimethylammonium bromide and sodium dodecyl sulphate were used to prepare the stable AgNPs [41]. The obtained AgNPs are in the size of $80 \mathrm{~nm}$. Bar et al., 2009, synthesized the silver nanoparticles using aqueous seed extract of J. curcas and no toxic chemicals are used as reducing and stabilizing agent during the synthesis. Characteristic surface plasmon absorption bands are observed at $425 \mathrm{~nm}$ for the reddish-yellow coloured silver nanoparticles synthesized from $10^{-3} \mathrm{M} \mathrm{AgNO}_{3}$. In HRTEM, the particles are predominantly spherical in shape with diameter ranging from 15 to $25 \mathrm{~nm}$. Larger and uneven shaped particles with diameter $30-50 \mathrm{~nm}$ are also obtained. Here, Jatropha seed extract, which is environmentally benign and renewable, acts as both reducing and stabilizing agent. Ag nanoparticles prepared in this process are quiet stable and remain intact for nearly two months if they are protected under light proof conditions [42].

Biosynthesis of copper, zero-valent iron, and silver nanoparticles using leaf extract of Dodonaea viscosa has been investigated by Daniel et al., 2013. The synthesized nanoparticles showed spherical morphology and the average size of 29,27 , and $16 \mathrm{~nm}$ for $\mathrm{Cu}$, zero-valent iron, and $\mathrm{Ag}$ nanoparticles, respectively. Finally, biosynthesized $\mathrm{Cu}$, Zerovalent iron, and Ag nanoparticles were tested against human pathogens, namely, Gram-negative Escherichia coli, Klebsiella pneumonia, Pseudomonas fluorescens, and Gram-positive Staphylococcus aureus and Bacillus subtilis, and showed good antimicrobial activity. Also, the plausible reduction mechanism of metal into nanoparticles by Dodonaea viscosa leaf extract was reported (Figure 9) [43].

$\mathrm{Cu}_{2} \mathrm{O}$ nanoparticles were synthesized and were made as composite with polyvinyl alcohol. The nanoparticles were prepared by using Manihot esculenta leaves containing reducing sugars which act as a reducing agent. The obtained $\mathrm{Cu}_{2} \mathrm{O}$ nanoparticles and $\mathrm{Cu}_{2} \mathrm{O} / \mathrm{PVA}$ composite were characterized by XRD, SEM, UV-vis absorption, and FTIR [44].

In this paper, the authors have focused on the agricultural waste biosynthesis of silver nanoparticles by A. hypogaea leaf extract, which gave an average particle sizes from 7 to $8 \mathrm{~nm}$. The synthesized silver nanoparticles were coated on glass substrates, and morphological properties were characterized by SEM analysis. Also, the prepared nanoparticles were analyzed with various pathogens like K. pneumoniae, Pseudomonas species, Proteus species, and E. coli which has shown a good inhibition against the selected pathogens [45].

The present study deals with a green, low-cost, and reproducible method for the synthesis of $\mathrm{Cu}_{2} \mathrm{O}$ nanoparticles by the reduction of Barfoed's solution using agriculture wastes of A. hypogaea leaf extracts. The extract contains reducing sugars which are responsible for the formation of nanoparticles. The aldehyde group present in the reducing sugar plays excellent role in the formation of cuprous oxide nanoparticles in the solution. Antibacterial effect of cuprous oxide nanoparticles against Gram-negative E. coli was analyzed. The resulting $\mathrm{Cu}_{2} \mathrm{O}$ nanoparticles were characterized by XRD, SEM, UV-visible spectroscopy, and FTIR spectroscopy [46].

2.7. Pollen Grains as Biotemplate. Bioinspired hierarchical mesoporous $\mathrm{TiO}_{2}$ photocatalysts are prepared by using pollen grains as biotemplate. The physicochemical properties of the samples are characterized in detail by Xray diffraction analysis, scanning electron microscopy, $\mathrm{X}$ ray photoelectron spectroscopy, and nitrogen adsorptiondesorption isotherms. Results indicate that the as-prepared products have a similar structure with the pollen grains, which maintain the ellipsoidal shape and the open pores networks on reticular shells [47].

Xulai et al., 2012, prepared the lithium silicate from rice hulls (Figure 4(j)). They have utilized the silica nanoparticles in rice hulls as the silicon source, and by mixing with lithium carbonate, hydroxide and acetate lithium silicate nanoparticles are obtained from rice hulls. The inventive method is an environment-friendly process and has low preparation cost [48].

Silver nanoparticles were prepared by pomegranate peel extract as a reducing agent. The extract was challenged with $\mathrm{AgNO}_{3}$ solution for the production of AgNPs. The reaction process was simple for the formation of highly stable $\mathrm{Ag}$ nanoparticles at room temperature by the biowaste of the fruit. The morphol (Figure 12) and crystal phase of the NPs 


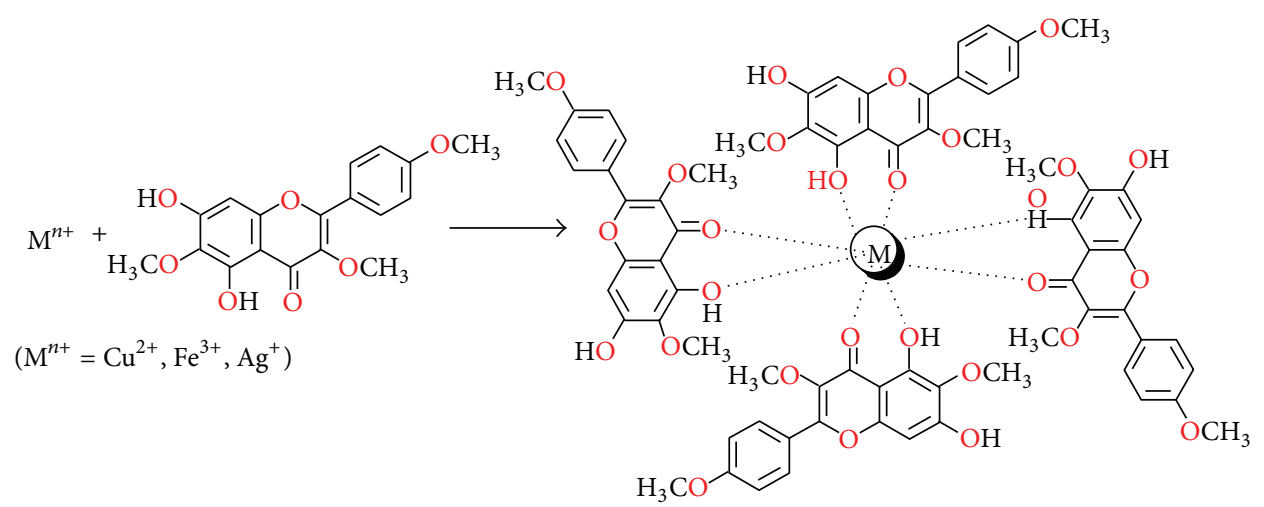

(Adapted from Daniel et al., 2013)

FIgURE 9: Reduction mechanism of metal into nanoparticles by Dodonaea viscosa leaf extract.

were detected. TEM studies showed that the Ag nanoparticles obtained were of sizes $5 \pm 1.5 \mathrm{~nm}$ [49].

2.8. Low-Cost Approach for the Synthesis of Nanoparticles. Pei et al., 2012, have reported the preparation of gold nanoparticles by utilizing the palm oil mill effluent without the addition of any external surfactant or capping agent. The prepared were characterized by FT-IR, UV-visible spectroscopy, TEM, and powder XRD spectroscopy. The obtained gold nanoparticles were triangular and hexagonal in shape [50].

The authors have studied the preparation of $\mathrm{SiC}$ nanoparticles by using direct pyrolysis of rice husk. Rice husk used in this study was treated with a silica source in order to enrich the silica content. The synthesis was carried out in an argon atom at $1600^{\circ} \mathrm{C}$. The SEM study of pyrolyzed rice husk shows that whiskers were formed in the silica rich zone and particles were formed in the carbon rich zone. Thus, by utilizing the agricultural waste rice husk $\mathrm{SiC}$ nanoparticles were produced [51].

2.9. Agricultural Waste Ash as Source. The composite materials which contain $\mathrm{SiC}$ were prepared from the agricultural waste materials such as fruit shells, fruit cores, rice husk, corn cob litter, and weeds [65]. The $\mathrm{SiC}$ was prepared by calcining the agricultural waste and placing it in a $400-$ $1200^{\circ} \mathrm{C}$ furnace for $0.5-8 \mathrm{~h}$ in inert gas protection condition. The obtained residue was added with $0.05-1 \mathrm{M}$ metal salt solution. The metal salt solution is nitrate solution of $\mathrm{Mn}$ (II), $\mathrm{Fe}(\mathrm{III}), \mathrm{Ni}(\mathrm{II}), \mathrm{Co}(\mathrm{II})$, or $\mathrm{Zn}(\mathrm{II})$. The obtained product is characterized by nanoporous structure, excellent adsorption, catalytic performance, and electromagnetic absorption property which can be used for wastewater treatment and waveabsorbing material.

Mesoporous silica nanoparticles with a spherical were prepared from rice husk (Figure $4(\mathrm{j})$ ) by sol-gel technique at ambient condition. TEM analysis revealed the formation of silica nanoparticles of $50.9 \mathrm{~nm}$ [52]. Yulin et al., 2011, reported the synthesis of Si nanoparticles by using the rice hull ash. The speed of addition of $\mathrm{H}_{2} \mathrm{SO}_{4}$ and concentration of the ash determine the size of the nanoparticles. The optimum preparation of small-size nanosilica involved the mixing of sodium silica solution (11.8\%) and the adding speed of $\mathrm{H}_{2} \mathrm{SO}_{4}$ solution $(14.5 \mathrm{~mL} / \mathrm{min})$, and its size was $30 \mathrm{~nm}$ [53]. The synthesis of nanoparticles silica oxide from rice husk, sugar cane bagasse, and coffee husk by employing vermicompost with Eisenia foetida was reported. The product is calcinated and recovered as crystalline nanoparticles. XRD, TEM, and DLS showed crystalline phases of particles [66].

Rajani et al., 2010, reported the synthesis of silver nanoparticles with the help of agricultural crop waste. Four pulse crop plants and three cereal crop plants such as Vigna radiata, Arachis hypogaea, Cyamopsis tetragonolobus, Zea mays, Pennisetum glaucum, and Sorghum vulgare were used and compared for their extracellular synthesis of metallic silver nanoparticles. The prepared silver nanoparticles were characterized by UV-visible spectroscopy, XRD, SEM, and EDAX [54].

2.10. Cocos nucifera Coir Extract as Green Source. One of the most useful plants is coconut palm, Cocos nucifera. Botanically, the coconut fruit is a drupe, not a true, nut. Like other fruits, it has three layers: exocarp, mesocarp, and endocarp. The exocarp and mesocarp make up the husk of the coconut. The mesocarp is composed of fibers called coir which have many traditional and commercial uses. Anyhow, agricultural production leaves considerable amounts of agricultural waste. Cocos nucifera coir extracts have been used as a reducing and capping agent for the synthesis of AgNPs. The average particle size measured from the TEM images histogram is observed to be $23 \pm 2 \mathrm{~nm}$ [17]. Also, AgNPs were screened for larvicidal assay. The result proved that Ag nanoparticles were effective antilarvicidal agents against $A$. stephensi and C. quinquefasciatus (Figure 10) [17].

Thus, generally discarded crop waste was effectively used as an alternative method for the synthesis of nanoparticles (Figure 11). These bioinspired nanoparticles could, in turn, and applications in catalysis, sensors, medicine and making active membranes. This review shows the feasibility of using agrowaste material for the biosynthesis of nanoparticles, 

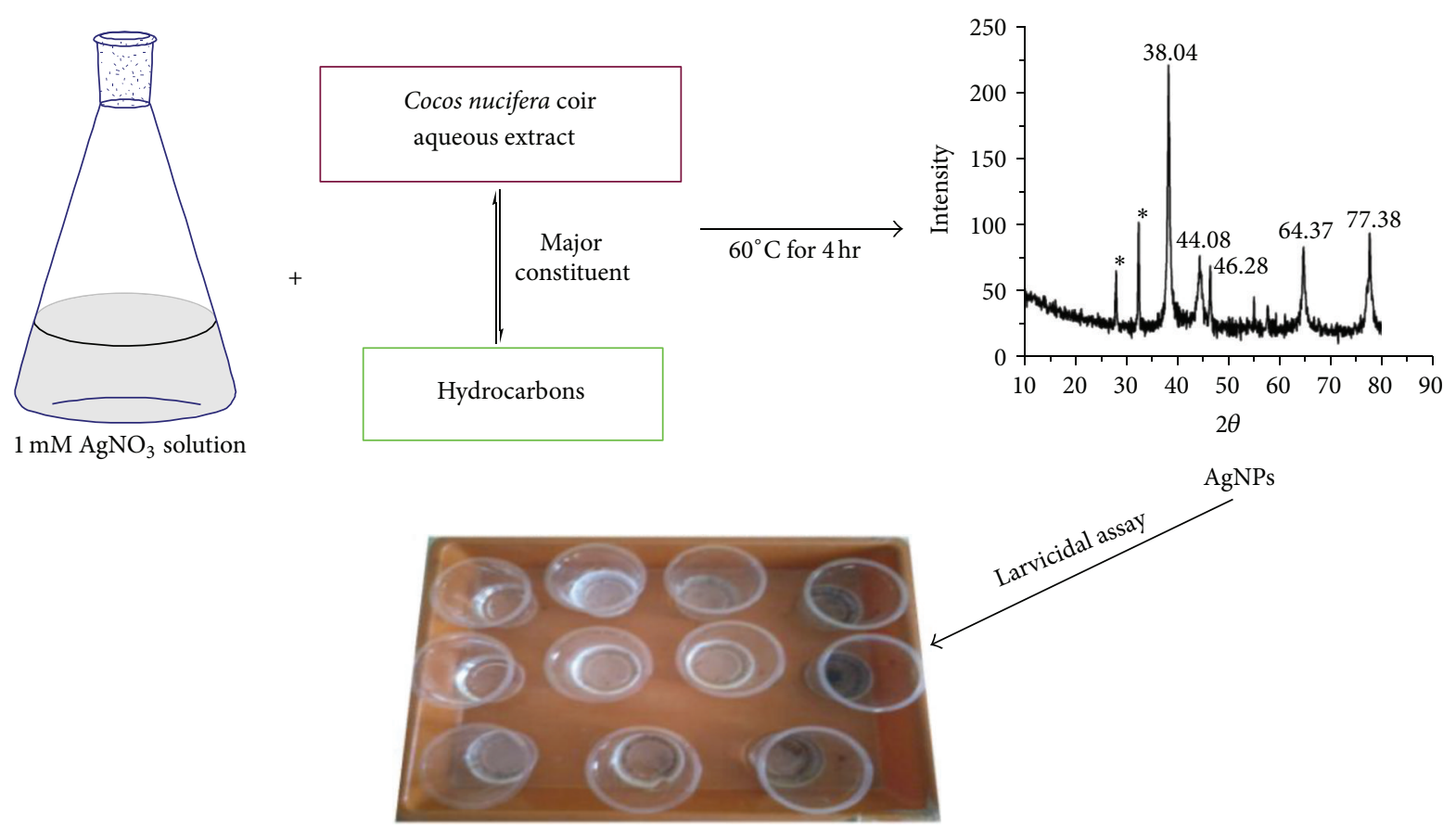

FIGURE 10: C. nucifera coir mediated Ag nanoparticles preparation (adapted from [17]).
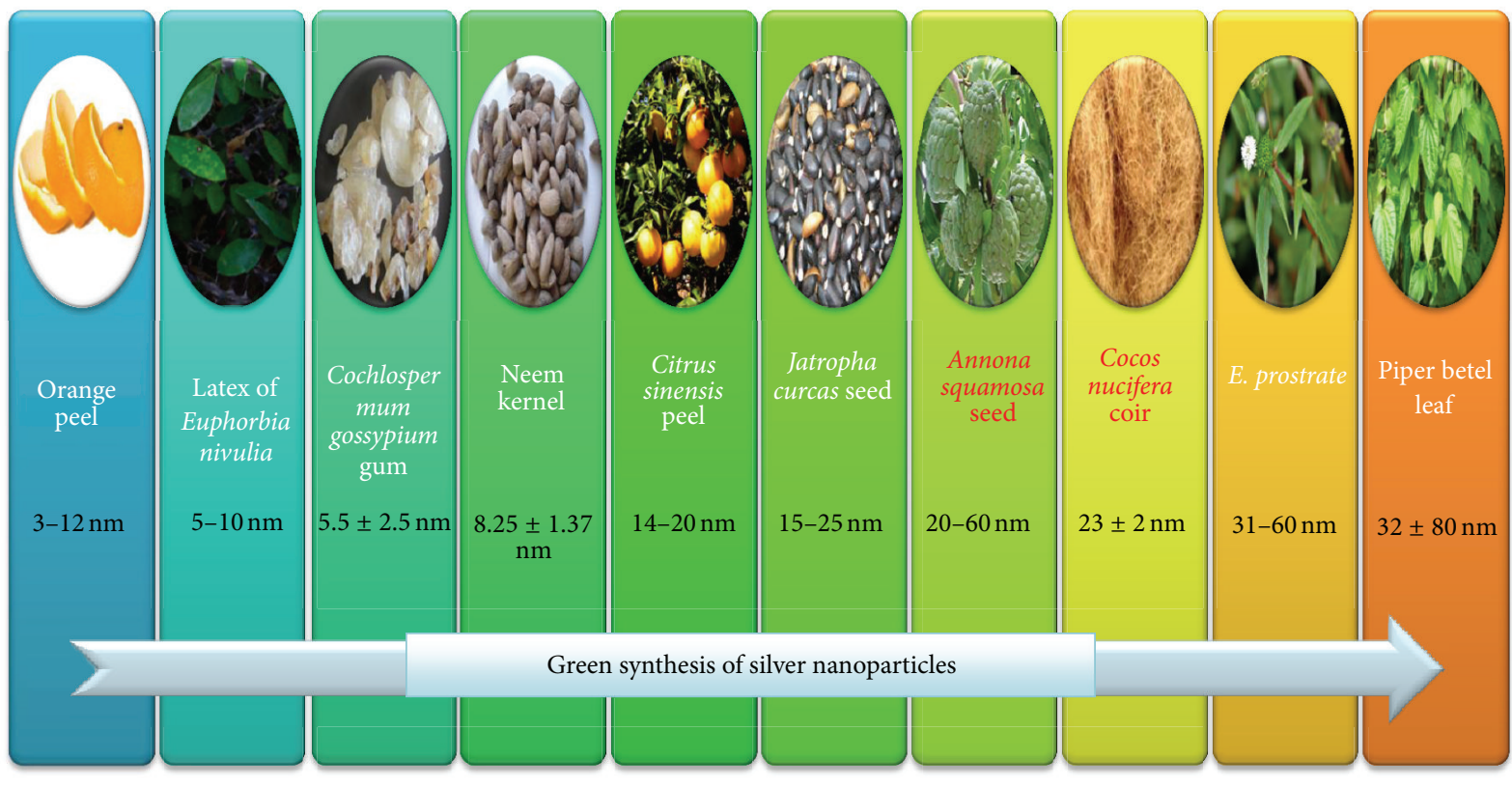

FIGURE 11: Green synthesis of silver nanoparticles using various natural resources.

which is potentially more scalable and economic due to its lower cost.

\section{Conclusions}

Increasing awareness towards green chemistry and biological processes has led to a desire to develop an environmentfriendly approach for the synthesis of nontoxic nanoparticles. Unlike other processes in physical and chemical methods, devastated crops act as a medium for biosynthesis of nanoparticles and cost-effective and ecofriendly approach. Therefore, crop waste synthesis of nanoparticles has emerged as an important branch of nanobiotechnology. Due to their rich diversity and the innate potential for the synthesis of nanoparticles, they could be regarded as potential biofactories for nanoparticles synthesis. Future research on devastated crop synthesis of nanoparticles would bring the uniform shape, size, and stable nanoparticles which are of 


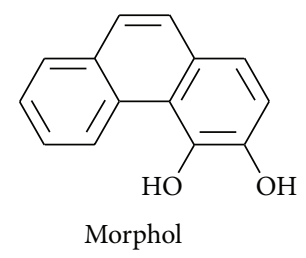

Figure 12

great importance for applications in the areas of chemistry, electronics, medicine, and agriculture. The use of agricultural crop waste for preparation of metal nanoparticles would add a new dimension to the agricultural sector in the utilization of crop waste.

\section{Authors' Contribution}

G. Madhumitha and Selvaraj Mohana Roopan equally contributed to the preparation of this paper.

\section{References}

[1] J. H. Fendler, Ed., Nanoparticles and Nanostructured Films: Preparation, Characterization and Applications, John Wiley \& Son, New York, NY, USA, 1998.

[2] T. S. Wong and U. Schwaneberg, "Protein engineering in bioelectrocatalysis," Current Opinion in Biotechnology, vol. 14, no. 6, pp. 590-596, 2003.

[3] A. Ramanavicius, A. Kausaite, and A. Ramanaviciene, "Biofuel cell based on direct bioelectrocatalysis," Biosensors and Bioelectronics, vol. 20, no. 10, pp. 1962-1967, 2005.

[4] N. Duran and A. B. Seabra, "Metallic oxide nanoparticles: state of the art in biogenic syntheses and their mechanisms," Applied Microbiology and Biotechnology, vol. 95, no. 2, pp. 275-288, 2012.

[5] H. Korbekandi, S. Iravani, and S. Abbasi, "Production of nanoparticles using organisms production of nanoparticles using organisms," Critical Reviews in Biotechnology, vol. 29, no. 4, pp. 279-306, 2009.

[6] T. Luangpipat, I. R. Beattie, Y. Chisti, and R. G. Haverkamp, "Gold nanoparticles produced in a microalga," Journal of Nanoparticle Research, vol. 13, pp. 6439-6445, 2011.

[7] K. N. Thakkar, S. S. Mhatre, and R. Y. Parikh, "Biological synthesis of metallic nanoparticles," Nanomedicine: Nanotechnology, Biology, and Medicine, vol. 6, no. 2, pp. 257-262, 2010.

[8] J. A. Dahl, B. L. S. Maddux, and J. E. Hutchison, “Toward greener nanosynthesis," Chemical Reviews, vol. 107, no. 6, pp. 2228-2269, 2007.

[9] S. S. Shankar, A. Ahmad, and M. Sastry, "Geranium leaf assisted biosynthesis of silver nanoparticles," Biotechnology Progress, vol. 19, pp. 1627-1631, 2003.

[10] P. Raveendran, J. Fu, and S. L. Wallen, "Completely green synthesis and stabilization of metal nanoparticles," Journal of American Chemical Society, vol. 125, no. 46, pp. 13940-13941, 2003.

[11] I. R. Beattie and R. G. Haverkamp, "Silver and gold nanoparticles in plants: sites for the reduction to metal," Metallomics, vol. 3, pp. 628-632, 2011.

[12] M. Gericke and A. Pinches, "Biological synthesis of metal nanoparticles," Hydrometallurgy, vol. 83, no. 1-4, pp. 132-140, 2006.
[13] S. Iravani, "Green synthesis of metal nanoparticles using plants," Green Chemistry, vol. 13, pp. 2638-2650, 2011.

[14] K. Velayutham, A. A. Rahuman, G. Rajakumar et al., "Larvicidal activity of green synthesized silver nanoparticles using bark aqueous extract of Ficus racemosa against Culex quinquefasciatus and Culex gelidus," Asian Pacific Journal of Tropical Medicine, vol. 6, pp. 95-101, 2013.

[15] K. Mukunthan and S. Balaji, "Cashew apple juice (Anacardium occidentale L.) speeds up the synthesis of silver nanoparticles," International Journal of Green Nanotechnology, vol. 4, pp. 71-79, 2012.

[16] R. G. Haverkamp and A. T. Marshall, "The mechanism of metal nanoparticle formation in plants: limits on accumulation," Journal of Nanoparticle Research, vol. 11, no. 6, pp. 1453-1463, 2009.

[17] S. M. Roopan, G. M. Rohit, A. A. Rahuman, C. Kamaraj, A. Bharathi, and T. V. Surendra, "Low-cost and eco-friendly phyto-synthesis of silver nanoparticles using Cocos nucifera coir extract and its larvicidal activity," Industrial Crops and Products, vol. 43, pp. 631-635, 2013.

[18] R. B. A. J. Koraa, R. B. Sashidharb, and J. Arunachalama, "Aqueous extract of gum olibanum (Boswellia serrata): a reductant and stabilizer for the biosynthesis of antibacterial silver nanoparticles," Process Biochemistry, vol. 47, pp. 1516-1520, 2012.

[19] S. V. Patil, H. P. Borase, C. D. Patil, and B. K. Salunke, "Biosynthesis of silver nanoparticles using latex from few Euphorbian plants and their antimicrobial potential," Applied Biochemistry and Biotechnology, vol. 167, no. 4, pp. 776-790, 2012.

[20] V. T. P. Vinod, P. Saravanan, B. Sreedhar, D. K. Devi, and R. B. Sashidhar, "A facile synthesis and characterization of Ag, $\mathrm{Au}$ and $\mathrm{Pt}$ nanoparticles using a natural hydrocolloid gum kondagogu (Cochlospermum gossypium)," Colloids and Surfaces B: Biointerfaces, vol. 83, no. 2, pp. 291-298, 2011.

[21] M. Valodkara, P. S. Nagarb, and R. N. Jadejac, "Euphorbiaceae latex induced green synthesis of non-cytotoxic metallic nanoparticle solutions: a rational approach to antimicrobial applications," Colloids and Surfaces A: Physicochemical and Engineering Aspects, vol. 384, pp. 337-344, 2011.

[22] T. C. Prathna, N. Chandrasekaran, A. M. Raichur, and A. Mukherjee, "Biomimetic synthesis of silver nanoparticles by Citrus limon (lemon) aqueous extract and theoretical prediction of particle size," Colloids and Surfaces B: Biointerfaces, vol. 82, no. 1, pp. 152-159, 2011.

[23] R. Konwarh, B. Gogoi, R. Philip, M. A. Laskar, and N. Karak, "Biomimetic preparation of polymer-supported free radical scavenging, cytocompatible and antimicrobial "green" silver nanoparticles using aqueous extract of Citrus sinensis peel," Colloids and Surfaces B: Biointerfaces, vol. 84, no. 2, pp. 338-345, 2011.

[24] C. Carlson, S. M. Hussein, A. M. Schrand et al., "Unique cellular interaction of silver nanoparticles: size-dependent generation of reactive oxygen species," Journal of Physical Chemistry B, vol. 112, no. 43, pp. 13608-13619, 2008.

[25] M. Singh, S. Singh, S. Prasad, and I. S. Gambhir, "Nanotechnology in medicine and antibacterial effect of silver nanoparticles," Digest Journal of Nanomaterials and Biostructures, vol. 3, pp. 115-122, 2008.

[26] S. Kaviya, J. Santhanalakshmi, B. Viswanathan, J. Muthumary, and K. Srinivasan, "Biosynthesis of silver nanoparticles using citrus sinensis peel extract and its antibacterial activity," Spectrochimica Acta A: Molecular and Biomolecular Spectroscopy, vol. 79, no. 3, pp. 594-598, 2011. 
[27] T. Happi Emaga, C. Robert, S. N. Ronkart, B. Wathelet, and M. Paquot, "Dietary fibre components and pectin chemical features of peels during ripening in banana and plantain varieties," Bioresource Technology, vol. 99, no. 10, pp. 4346-4354, 2008.

[28] A. Bankar, B. Joshi, A. R. Kumar, and S. Zinjarde, "Banana peel extract mediated novel route for the synthesis of palladium nanoparticles," Materials Letters, vol. 64, pp. 1951-1953, 2010.

[29] V. K. Shukla, R. S. Yadav, P. Yadav, and A. C. Pandey, “Green synthesis of nanosilver as a sensor for detection of hydrogen peroxide in water," Journal of Hazardous Materials, vol. 213- 214, pp. 161-166, 2012.

[30] G. Madhumitha, G. Rajakumar, S. M. Roopan et al., "Acaricidal, insecticidal, and larvicidal efficacy of fruit peel of aqueous extract of Annona squamosa and its compounds against bloodfeeding parasites," Parasitology Research, vol. 111, pp. 2189-2199, 2012.

[31] S. M. Roopan, A. Bharathi, R. Kumar, V. G. Khanna, and A. Prabhakarn, "Acaricidal, insecticidal, and larvicidal efficacy of aqueous extract of Annona squamosa L. peel as biomaterial for the reduction of palladium salts into nanoparticles," Colloids and Surfaces B: Biointerfaces, vol. 92, pp. 209-212, 2012.

[32] S. M. Roopan, A. Bharathi, A. Prabhakarn et al., "Efficient phyto-synthesis and structural characterization of rutile $\mathrm{TiO}_{2}$ nanoparticles using Annona squamosa peel extract," Spectrochimica Acta: Molecular and Biomolecular Spectroscopy, vol. 98, pp. 86-90, 2012.

[33] R. M. Gengan, K. Anand, A. Phulukdaree, and A. Chuturgoon, "A549 lung cell line activity of biosynthesized silver nanoparticles using Albizia adianthifolia leaf," Colloids and Surfaces B: Biointerfaces, vol. 105, pp. 87-91, 2013.

[34] G. Madhumitha, A. M. Saral, B. Senthilkumar, and A. Sivaraj, "Hepatoprotective potential of petroleum ether leaf extract of Crossandra infundibuliformis on $\mathrm{CCl} 4$ induced liver toxicity in albino mice," Asian Pacific Journal of Tropical Medicine, vol. 3, no. 10, pp. 788-790, 2010.

[35] G. Madhumitha and A. M. Saral, "Preliminary phytochemical analysis, antibacterial, antifungal and anticandidal activities of successive extracts of Crossandra infundibuliformis," Asian Pacific Journal of Tropical Medicine, pp. 192-195, 2011.

[36] D. Philip, "Green synthesis of gold and silver nanoparticles using Hibiscus rosasinensis," Physica E, vol. 42, no. 5, pp. 14171424, 2010.

[37] S. Kumar, Y. S. Negi, and J. S. Upadhyaya, "Studies on characterization of corn cob based nanoparticles," Advanced Materials Letters, vol. 1, pp. 246-253, 2010.

[38] D. Raghunandan, B. D. Mahesh, S. Basavaraja, S. D. Balaji, S. Y. Manjunath, and A. Venkataraman, "Microwave-assisted rapid extracellular synthesis of stable bio-functionalized silver nanoparticles from guava (Psidium guajava) leaf extract," Journal of Nanoparticles Research, vol. 13, no. 5, pp. 2021-2028, 2011.

[39] G. Rajakumar and A. Abdul Rahuman, "Larvicidal activity of synthesized silver nanoparticles using Eclipta prostrata leaf extract against filariasis and malaria vectors," Acta Tropica, vol. 118, no. 3, pp. 196-203, 2011.

[40] K. Raja, A. Saravanakumar, and R. Vijayakumar, "Efficient synthesis of silver nanoparticles from Prosopis juliflora leaf extract and its antimicrobial activity using sewage," Spectrochimica Acta A: Molecular and Biomolecular Spectroscopy, vol. 97, pp. 490494, 2012.

[41] Z. Khan, O. Bashir, J. I. Hussain, S. Kumar, and R. Ahmad, "Effects of ionic surfactants on the morphology of silver nanoparticles using Paan (Piper betel) leaf petiole extract," Colloids and Surfaces B: Biointerfaces, vol. 98, pp. 85-90, 2012.

[42] H. Bar, D. K. Bhui, G. P. Sahoo, P. Sarkar, S. P. De, and A. Misra, "Green synthesis of silver nanoparticles using latex of Jatropha curcas," Colloids and Surfaces A: Physicochemical and Engineering Aspects, vol. 339, no. 1-3, pp. 134-139, 2009.

[43] S. C. G. K. Daniel, G. Vinothini, N. Subramanian, K. Nehru, and M. Sivakumar, "Biosynthesis of $\mathrm{Cu}, \mathrm{ZVI}$, and Ag nanoparticles using Dodonaea viscosa extract for antibacterial activity against human pathogens," Journal of Nanoparticle Research, vol. 15, pp. 1-10, 2013.

[44] C. Ramesh, M. Hariprasad, V. Ragunathan, and N. Jayakumar, "A novel route for synthesis and characterization of green $\mathrm{Cu}_{2} \mathrm{O} / \mathrm{PVA}$ nano composites," European Journal of Applied Engineering and Scientific Research, vol. 1, pp. 201-206, 2012.

[45] M. HariPrasad, D. Kalpana, and K. N. Jaya, "Silver nano coating on glass substrate and antibacterial activity of silver nano particles synthesised by Arachis hypogaea L. leaf extract," Current Nanoscience, vol. 8, pp. 280-285, 2012.

[46] C. Ramesh, M. Hari Prasad, and V. Ragunathan, "Effect of Arachis hypogaeaL. leaf extract on Barfoed's solution, green synthesis of $\mathrm{Cu}_{2} \mathrm{O}$ nanoparticles and its antibacterial effect," Current Nanoscience, vol. 7, pp. 995-999, 2011.

[47] Z. He, W. Que, and Y. He, "Synthesis and characterization of bioinspired hierarchical mesoporous $\mathrm{TiO}_{2}$ photocatalysts," Materials Letters, vol. 94, pp. 136-139, 2013.

[48] Y. Xulai, Y. Maoping, X. Jia, and X. Xiaoming, "Method for preparing lithium silicate from rice hulls," Faming Zhuanli Shenqing CN, 102826561 A, 20121219, 2012.

[49] A. Naheed and S. Seema, "Biosynthesis of silver nanoparticles from biowaste pomegranate peels," International Journal of Nanoparticles, vol. 5, pp. 185-195, 2012.

[50] G. P. Pei, N. S. Han, H. Yan, and L. S. F. Yau, "Green synthesis of gold nanoparticles using palm oil mill effluent (POME): a lowcost and eco-friendly viable approach," Bioresource Technology, vol. 113, pp. 132-135, 2012.

[51] N. Kavitha, M. Balasubramanian, and V. Y. Deval, "Synthesis and characterization of nano silicon carbide power from agricultural waste," Transactions of the Indian Ceramic Society, vol. 70, pp. 115-118, 2011.

[52] A. Farook, C. Thiam-Seng, and A. Jeyashelly, "A simple template-free sol-gel synthesis of spherical nanosilica from agricultural biomass," Journal of Sol-Gel Science and Technology, vol. 59, pp. 580-583, 2011.

[53] L. Yulin, C. Zhengxing, L. Xiaoxuan, and Z. Huawei, "Preparation of nano size silica from rice hull ash," Asian Journal of Chemistry, vol. 23, no. 4, pp. 1822-1824, 2011.

[54] P. Rajani, K. SriSindhura, T. N. V. K. V. Prasad et al., "Fabrication of biogenic silver nanoparticles using agricultural crop plant leaf extracts," in Proceedings of the 1st International Conference on Advanced Nanomaterials and Nanotechnology (ICANN '09), pp. 148-153, December 2009.

[55] H. S. Parmar and A. Kar, "Medicinal values of fruit peels from Citrus sinensis, Punica granatum, and Musa paradisiaca with respect to alterations in tissue lipid peroxidation and serum concentration of glucose, insulin, and thyroid hormones," Journal of Medicinal Food, vol. 11, no. 2, pp. 376-381, 2008.

[56] H. K. Tewari, S. S. Marwaha, and K. Rupal, "Ethanol from banana peels," Agricultural Wastes, vol. 16, no. 2, pp. 135-146, 1986. 
[57] J. P. Essien, E. J. Akpan, and E. P. Essien, "Studies on mould growth and biomass production using waste banana peel," Bioresource Technology, vol. 96, no. 13, pp. 1451-1456, 2005.

[58] A. Bankar, B. Joshi, A. R. Kumar, and S. Zinjarde, "Banana peel extract mediated novel route for the synthesis of silver nanoparticles," Colloids and Surfaces A: Physicochemical and Engineering Aspects, vol. 368, pp. 58-63, 2010.

[59] A. Bankar, B. Joshi, A. R. Kumar, and S. Zinjarde, "Banana peel extract mediated synthesis of gold nanoparticles," Colloids Surface B: Biointerfaces, vol. 80, no. 1, pp. 45-50, 2010.

[60] R. Kumar, S. M. Roopan, A. Prabhakarn, V. G. Khanna, and S. Chakroborty, "Agricultural waste Annona squamosa peel extract: biosynthesis of silver nanoparticles," Spectrochimica Acta A: Molecular and Biomolecular Spectroscopy, vol. 90, pp. 173-176, 2012.

[61] G. Madhumitha and A. M. Saral, "Screening of Larvicidal activity of Crossandr infundibuliformis extracts against Anopheles stephensi, Aedes aegypti and Culex quinquefasciatus," International Journal of Pharmacy and Pharmaceutical Sciences, vol. 4, pp. 485-487, 2012.

[62] S. Kaviya, J. Santhanalakshmi, and B. Viswanathan, "Biosynthesis of silver nano-flakes by Crossandra infundibuliformis leaf extract," Materials Letters, vol. 67, no. 1, pp. 64-66, 2012.

[63] M. M. H. Khalil, E. H. Ismail, and F. El-Magdoub, "Biosynthesis of Au nanoparticles using olive leaf extract," Arabian Journal of Chemistry, vol. 5, pp. 431-437, 2010.

[64] P. Rajani, K. SriSindhura, T. N. V. K. V. Prasad et al., "Fabrication of biogenic silver nanoparticles using agricultural crop plant leaf extracts," in Proceedings of the 1st International Conference on Advanced Nanomaterials and Nanotechnology (ICANN '09), vol. 1276, pp. 148-153, December 2009.

[65] C. Xuegang, Y. Ying, L. Shuting et al., "Preparation method of light composite material containing $\mathrm{SiC}$ and magnetic metal nanoparticle from agricultural waste," Faming Zhuanli Shenqing, CN, 102229496 A, 20111102, 2011.

[66] A. Espíndola-Gonzalez, A. L. Martínez-Hernández, C. AngelesChávez, V. M. Castaño, and C. Velasco-Santos, "Novel crystalline $\mathrm{SiO}_{2}$ nanoparticles via annelids bioprocessing of agroindustrial wastes," Nanoscale Research Letters, vol. 5, no. 9, pp. 1408-1417, 2010. 

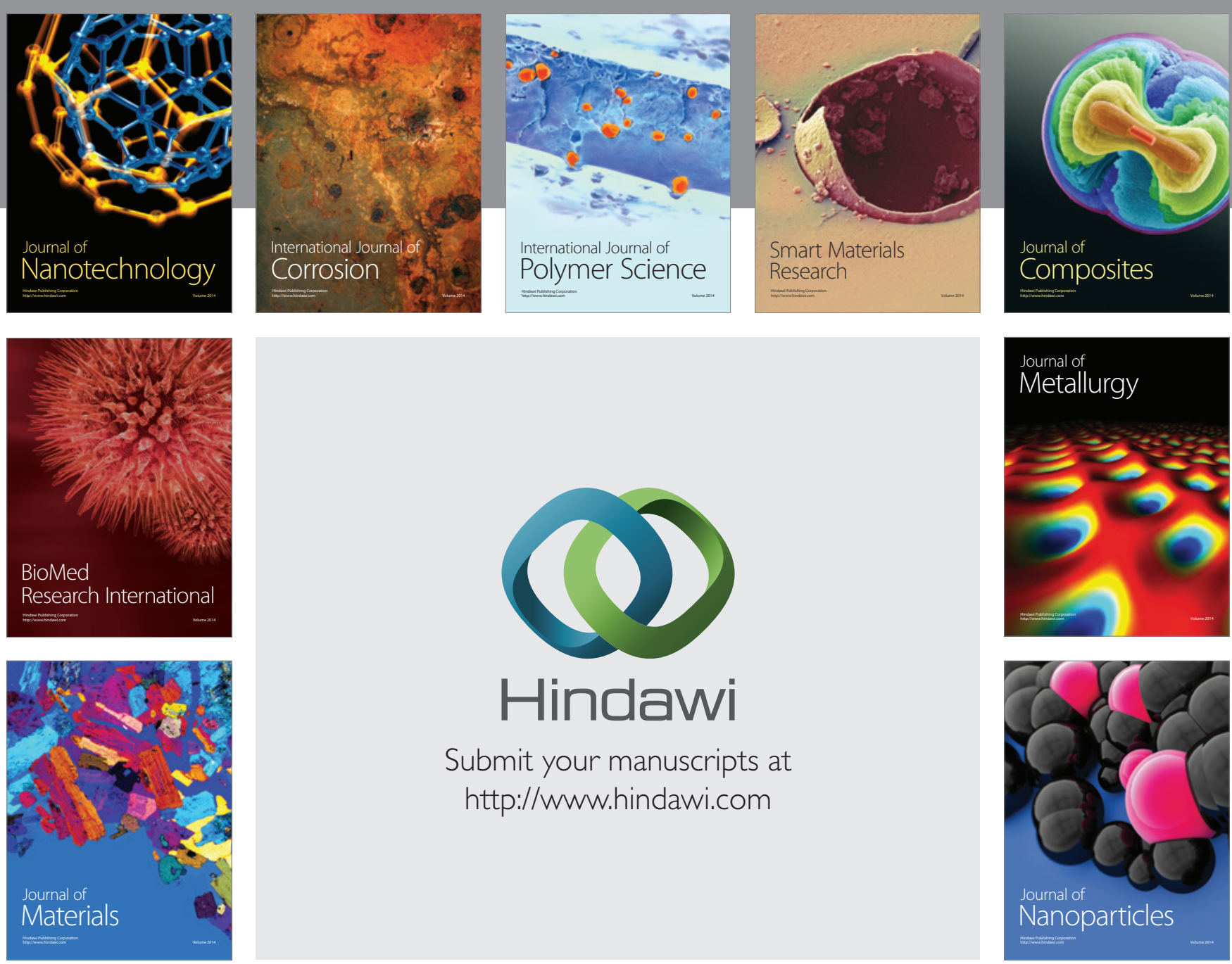

Submit your manuscripts at http://www.hindawi.com
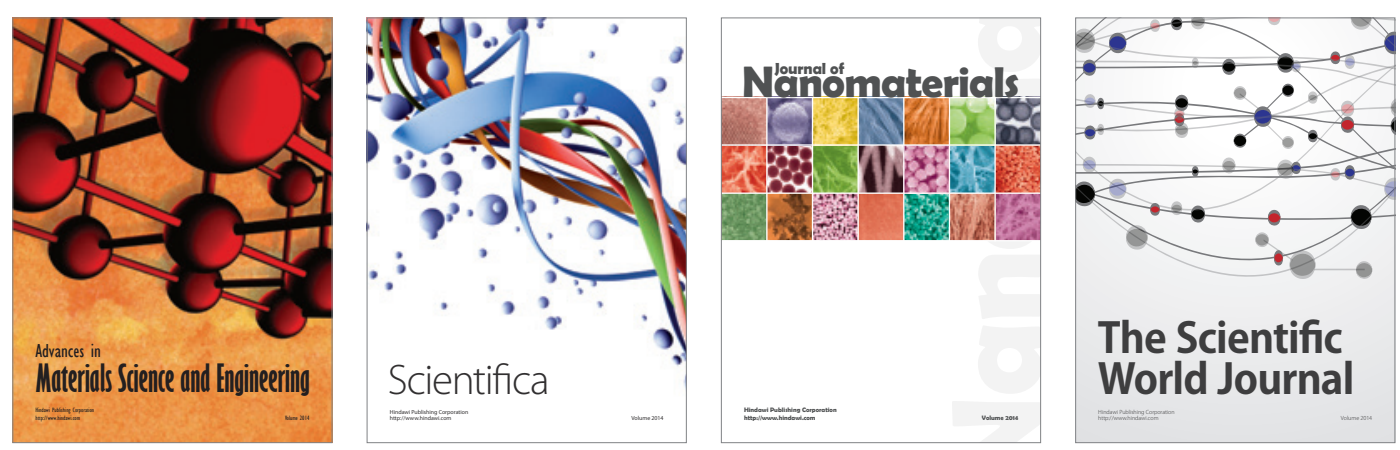

\section{The Scientific World Journal}
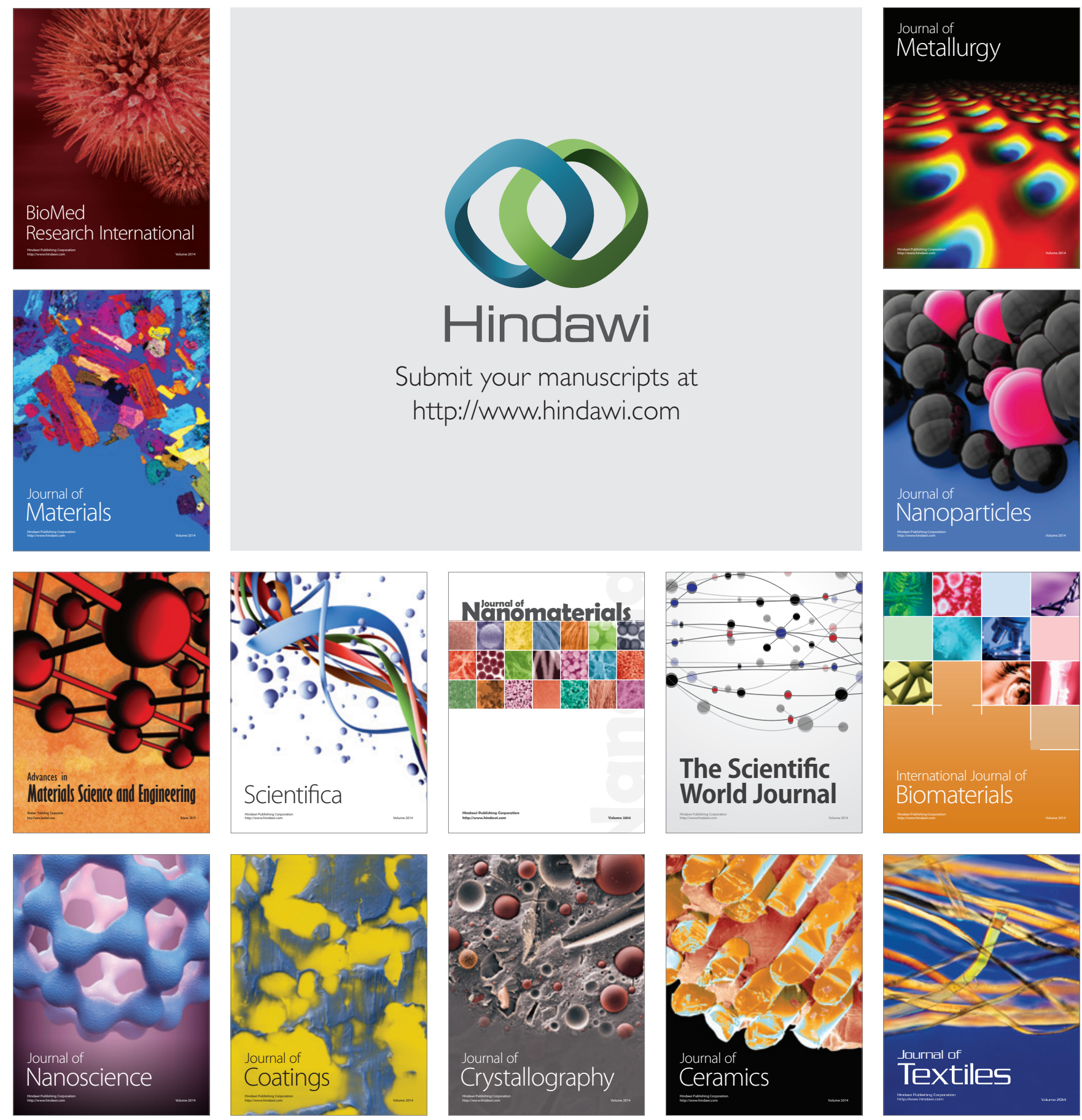